\title{
Adjunctive Testing in the Evaluation of Adults After Kawasaki Disease
}

\author{
Lori B. Daniels, MD; Jane C. Burns, MD
}

\begin{abstract}
Acute Kawasaki disease (KD) is diagnosed and treated by pediatricians, but decades later, these individuals are presenting to adult cardiologists with a variety of cardiovascular sequelae, including myocardial ischemia and infarction, congestive heart failure secondary to myocardial fibrosis, and claudication because of vascular insufficiency from thrombosed peripheral arteries. There are no clinical trials to guide management, interventions, and medical therapy in this patient population. This review summarizes the emerging information regarding evaluation of the cardiovascular status of adults decades after childhood KD. (Circ $J$ 2015; 79: 2299-2305)
\end{abstract}

\section{Key Words: Carotid arteries; Coronary computed tomography angiography; Kawasaki disease; Magnetic resonance imaging; Vasculature}

$\mathbf{K}$ awasaki Disease (KD) is a self-limited, acute vasculitis of unknown etiology that occurs predominantly in infants and young children under 5 years of age. It is a leading cause of childhood-acquired heart disease worldwide. Approximately $25 \%$ of untreated children develop coronary artery aneurysms, which can lead to myocardial infarction, ischemic heart disease, or sudden death., ${ }^{1,2}$ Beyond coronary artery aneurysms, there are conflicting data as to the degree of damage to the vasculature in KD patients, and the long-term ramifications of this, if any, with regards to future cardiovascular disease. Two additional areas of controversy regarding the prognosis of patients late after KD have also emerged. The first is whether patients, especially those with apparently normal coronary arteries or with transiently dilated coronary arteries, will have long-term cardiovascular sequelae. A second question is whether individuals after $\mathrm{KD}$ will develop accelerated atherosclerotic changes in the coronary arteries as a direct consequence of the inflammation in their arterial walls during the acute illness. ${ }^{3}$ There is ongoing debate about which $\mathrm{KD}$ patients need to be monitored long-term after KD, and which tests are indicated. ${ }^{4,5}$

To evaluate patients late after KD for evidence of dysfunction or structural changes in the coronary arteries and other vascular beds, a number of noninvasive tests have been studied. These include tests to assess endothelial cell function, carotid artery thickness and strain, and aortic and/or peripheral artery stiffness, as well as advanced imaging approaches involving either computed tomography (CT) or magnetic resonance imaging (MRI). The purpose of this article is to review the literature regarding adjunctive testing in the evaluation of adults with a history of KD.

\section{Noninvasive Assessment of Peripheral Arteries Endothelial Cell Function}

Endothelial cell dysfunction is a well-established marker of vascular risk that is strongly associated with traditional cardiovascular risk factors ${ }^{6}$ and is an independent predictor of incident cardiovascular events in healthy, low-risk populations. ${ }^{7-9}$ Endothelial dysfunction may be evident as early as adolescence in high-risk populations. ${ }^{10}$ Factors that can improve endothelial cell function include dietary, ${ }^{11,12}$ lifestyle, ${ }^{11}$ and pharmacologic interventions. ${ }^{13}$

In the setting of coronary artery disease or peripheral atherosclerosis, impaired endothelial cell function is associated with an increased risk of incident cardiovascular events. ${ }^{14,15}$ However, the vasculopathy of KD is distinct from that of typical atherosclerosis. ${ }^{4}$ There is no compelling reason to believe a priori that the associations between endothelial cell dysfunction and adverse cardiovascular outcomes, which are established for typical atherosclerosis, are also true of the vasculopathy seen after KD.

The gold standard for noninvasively assessing endothelial cell function is via ultrasound measurement of flow-mediated dilation (FMD) in response to reactive hyperemia in the brachial artery. ${ }^{16}$ However, this technique is very labor intensive, highly operator dependent, and requires expensive specialized equipment, making it impractical for routine use in clinical studies or clinical care. ${ }^{17,18}$ To overcome these technical obstacles, several alternate methods of assessing endothelial cell function have been developed. One of these, the Endo-PAT (Itamar Medical Ltd, Caesarea, Israel) assesses endothelial vasomotor function after reactive hyperemia by pulse amplitude tonometry (RH-PAT), as measured in the fingertips

Received September 29, 2015; accepted September 30, 2015; released online October 15, 2015

Division of Cardiology, Department of Medicine (L.B.D.), Department of Pediatrics (J.C.B.), University of California, San Diego, La Jolla, CA; Rady Children's Hospital San Diego, San Diego, CA (J.C.B.), USA

Mailing address: Lori B. Daniels, MD, MAS, FACC, Division of Cardiology, Department of Medicine, University of California, San Diego, Mail Code 7411, 9444 Medical Center Drive, La Jolla, CA 92037-7411, USA. E-mail: lbdaniels@ucsd.edu

ISSN-1346-9843 doi:10.1253/circj.CJ-15-0996

All rights are reserved to the Japanese Circulation Society. For permissions, please e-mail: cj@j-circ.or.jp 


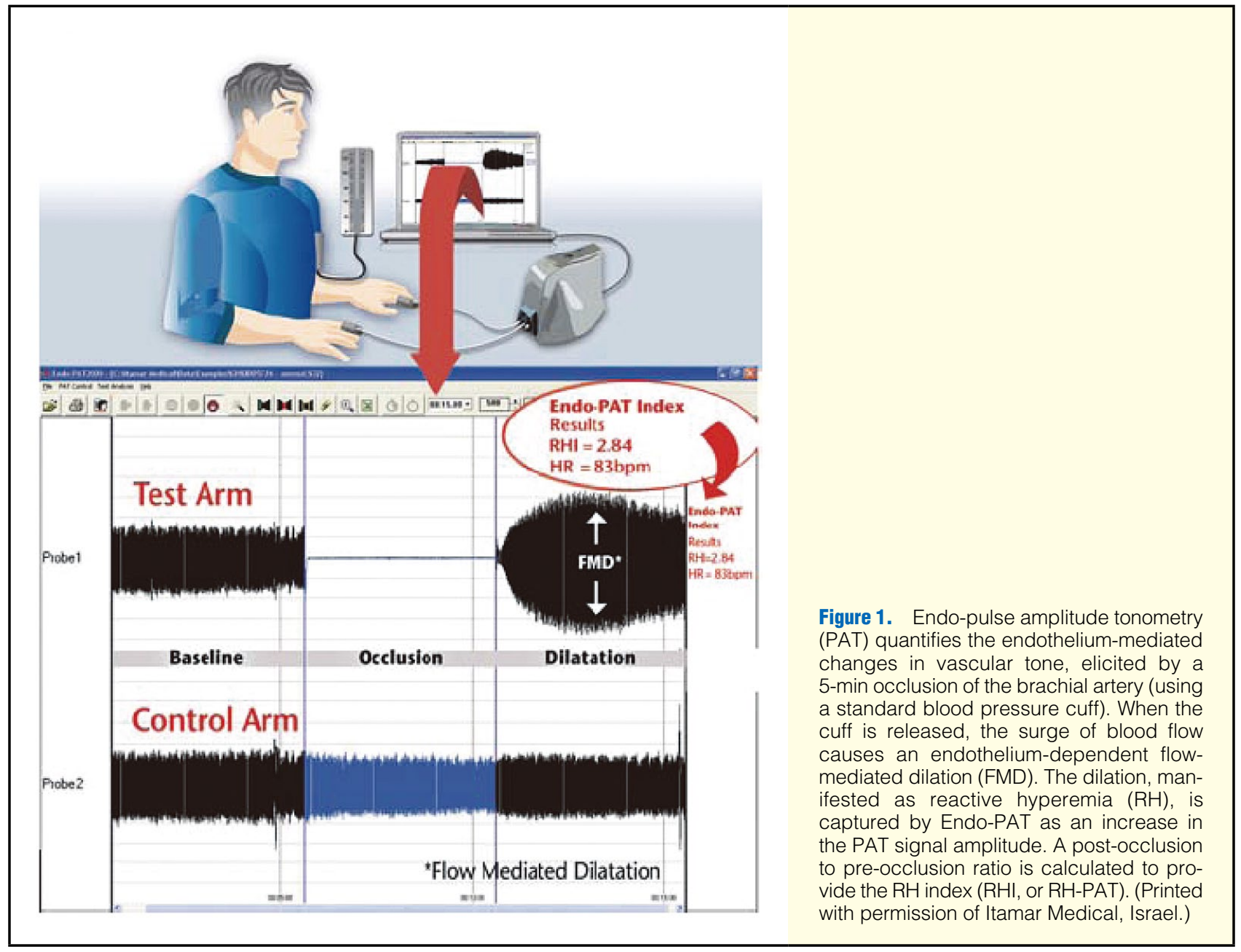

(Figure 1). ${ }^{17}$ As with FMD, a lower PAT value correlates with coronary atherosclerosis and cardiovascular events in both adults ${ }^{7}$ and children, ${ }^{19}$ though FMD and PAT may be measuring distinct aspects of endothelial function. ${ }^{20}$

Endothelial cell dysfunction has been documented late after $\mathrm{KD}$ in both coronary and systemic arteries after regression of aneurysms. ${ }^{21,22}$ Currently, there is some debate about whether endothelial dysfunction is pervasive in the KD population, as prior studies have yielded discrepant findings. A recent metaanalysis analyzed 18 studies of endothelial cell function in patients at various timepoints years after KD, and found extensive heterogeneity in the results. ${ }^{23}$ In general, most studies found poorer endothelial cell function in KD patients with coronary artery aneurysms compared with controls; however, results for subjects without aneurysms were more variable. None of the studies specifically analyzed the subgroup of patients with transiently dilated coronary arteries, and the implications for management and outcomes are unknown.

\section{Vascular Stiffness}

Arterial stiffness is an independent predictor of cardiovascular events in various populations..$^{24-29}$ Decreased arterial elasticity can be detected in childhood in those with cardiovascular risk factors. ${ }^{30,31}$ Arterial stiffness can be assessed noninvasively using pulse wave velocity (PWV) or the $\beta$ stiffness index (SI) of the carotid artery. ${ }^{32} \mathrm{PWV}$ measurement involves measuring the timing and magnitude of the reflected pressure wave that results when a pulse of blood encounters impedance as it moves through the arterial tree (Figure 2). Higher arterial stiffness results in an earlier reflected wave. Measurement of arterial PWV via simultaneous Doppler flow signals obtained from the carotid and femoral arteries is considered the gold standard, but brachial-ankle PWV is a technically easier alternative method. ${ }^{33}$ In adults with atherosclerotic disease, and in the general population, an increased arterial PWV is associated with an increased risk of cardiovascular events. ${ }^{28,34,35}$

Another way to assess vascular stiffness is via analysis of the carotid artery SI. The SI can be measured noninvasively using ultrasound and calculated based on the relation between systemic blood pressure and pulsatile changes in the arterial diameter. ${ }^{36}$ In small studies of selected cohorts, carotid SI is associated with adverse cardiovascular risk factors in children and with severity of coronary artery disease in adults after myocardial infarction, ${ }^{36,37}$ though there are limited data regarding SI and future cardiovascular risk.

In the subacute phase of KD, young children have evidence of stiffer carotid arteries than healthy controls. ${ }^{38}$ Beyond this timeframe, several studies have found evidence of increased carotid stiffness in KD patients with coronary artery aneurysms. ${ }^{23,39}$ However, whether carotid stiffness is also increased in KD patients without aneurysms remains controversial. ${ }^{40,41}$ In a meta-analysis that included 10 studies of carotid artery stiffness, the majority of studies found that KD patients had stiffer carotids than controls. ${ }^{23}$ However, this was primarily 
true in the studies that included large numbers of patients with coronary aneurysms. In contrast, 5 of 6 studies that included only patients without aneurysms did not show any difference in carotid stiffness.

Studies evaluating peripheral arterial stiffness in KD patients using PWV have more consistent results; 6 such studies showed stiffer vessels after KD regardless of the presence of coronary aneurysms, ${ }^{23,39,42-44}$ but half of the studies were conducted by the same group, and 1 found significantly stiffer arteries in men after KD, but not women. ${ }^{45}$ None of the studies separately evaluated patients with transiently dilated coronary arteries.

\section{Carotid Artery Intima Media Thickness (IMT)}

Measurement of the carotid IMT has been used and validated over the past few decades as a noninvasive surrogate measure of cardiovascular risk. ${ }^{46-49}$ Carotid IMT is associated with traditional cardiovascular risk factors, as well as with atherosclerosis in other vascular beds (including the coronary arteries), ${ }^{50}$ and with future vascular events. ${ }^{51}$ It is assessed by measuring the distance between the intima and media of the carotid artery wall, as imaged by B-mode ultrasound. There are a variety of protocols used to measure carotid IMT, but the most common involves averaging the thickness of the far wall of both the right and the left common carotid arteries. ${ }^{52} \mathrm{Sev}$ eral studies have established reference ranges for normal carotid IMT measurements in children and young adults. ${ }^{53-55}$

Assessment of studies of carotid IMT after KD is complicated by significant study heterogeneity, including differences in subjects' age, the time since acute KD, ethnicity, size of the study, and methodology. Specifically, carotid IMT may be increased early after the profound inflammation of acute KD, but is likely in many patients to subside with time, making the elapsed time since the acute illness a particularly relevant factor. With these caveats in mind, studies are split as to whether carotid IMT is increased in subjects overall after KD, compared with controls. Some studies comparing KD patients with coronary artery aneurysms found that this subset had increased carotid IMT compared with controls. ${ }^{40,43,56-58}$ Included in this group is the largest study of 203 subjects (plus 50 controls), in whom a difference in carotid IMT was seen primarily among those patients with giant aneurysms. ${ }^{59}$ The clinical significance of an increased carotid IMT after KD is unknown, as there are no longitudinal studies assessing any relationship between this and future cardiovascular events.

\section{Summary}

All these attempts to translate vascular assessments that have been validated for atherosclerotic heart disease for use in KD may share a flawed basic assumption. It is well documented that atherosclerosis is a diffuse inflammatory lesion that affects endothelial cell function and vessel architecture in a global manner. Although it is true that clinical complications may relate to specific vascular beds (eg, the coronary arteries or arteries supplying the lower limbs), the pathologic process is diffuse and affects all vascular beds to a greater or lesser degree. However, autopsy studies suggest that the same is not true for KD. Examination of different arteries decades after $\mathrm{KD}$ suggests that the major pathology is concentrated in the region of the aneurysms or remodeled aneurysms that occur predominantly in the coronary arteries and much less frequently in the brachial and iliofemoral arteries. Thus, the vascular insult and subsequent pathologic changes are really concentrated in a few vascular beds and the long-term sequelae are not diffuse. It follows that interrogation of the brachial artery, for example, may not be instructive regarding the structure

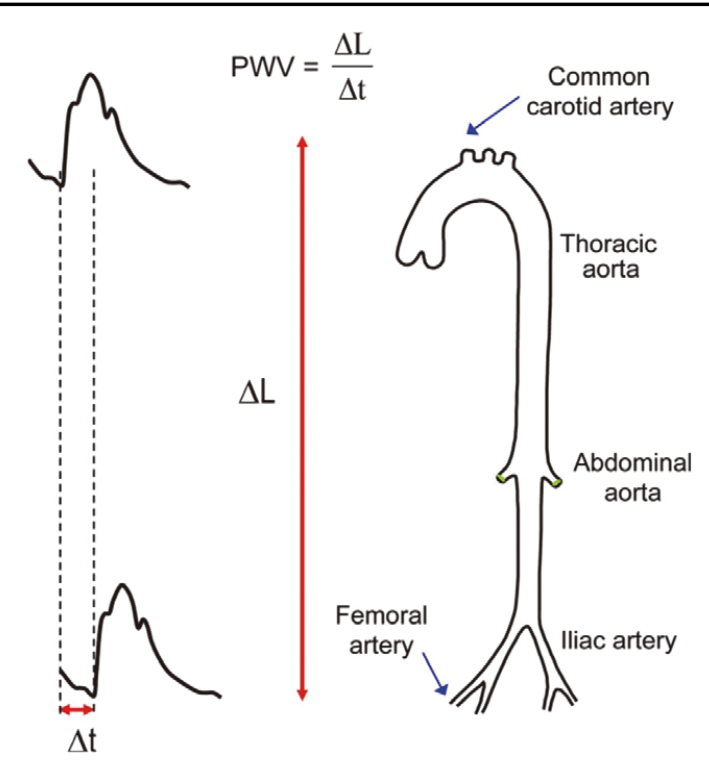

Figure 2. Measurement of carotid-femoral pulse wave velocity (PWV). PWV is calculated as $\Delta \mathrm{L}$ (meters)/ $/ \Delta \mathrm{t}$. Stiffer arteries will have higher PWV. (Reproduced with permission from Schillaci G, et al. ${ }^{81}$ )

and function of the coronary arteries late after KD. Therefore, caution must be exercised in interpreting the results of studies that have only been validated in patients with atherosclerosis.

\section{Advanced Imaging for Detection of Late Complications \\ Coronary Artery Calcium Score}

Calcium scoring by multi-slice CT is used to risk stratify patients with atherosclerotic heart disease and is a powerful predictor of mortality. ${ }^{60}$ Using electron beam CT calcium scoring to study 79 Japanese patients 2 months to 20 years after KD onset, a positive calcium score was detected only in those individuals with coronary artery aneurysms at least $6 \mathrm{~mm}$ in diameter. ${ }^{61} \mathrm{In}$ a study of a mixed ethnic population of 70 individuals with a median interval of 15 years between KD onset and multi-slice CT calcium scoring, $11(16 \%)$ had a positive score. ${ }^{62}$ All had coronary artery abnormalities documented during the acute phase of their KD and no individual with normal echocardiograms had detectable calcium. The sensitivity of calcium scoring for detection of coronary artery aneurysms or dilation was $100 \%$ when the scoring was performed at least 10 years after disease onset. This suggests that CT calcium scoring is a lowradiation, low-cost method for screening young adults with a history of KD whose initial echocardiographic results may not be known. At our center, all adolescent and young adult KD patients are screened using a CT calcium score before being released from further surveillance to ensure that no coronary arterial lesions are missed.

\section{CT Angiography (CTA)}

Adults who developed coronary artery aneurysms during the acute phase of KD require life-long monitoring for late complications, including myocardial ischemia caused by stenosis or thrombosis in the damaged arterial segments and myocardial fibrosis. The goals of imaging are three-fold: (1) to assess structural changes in the coronary arteries associated with 

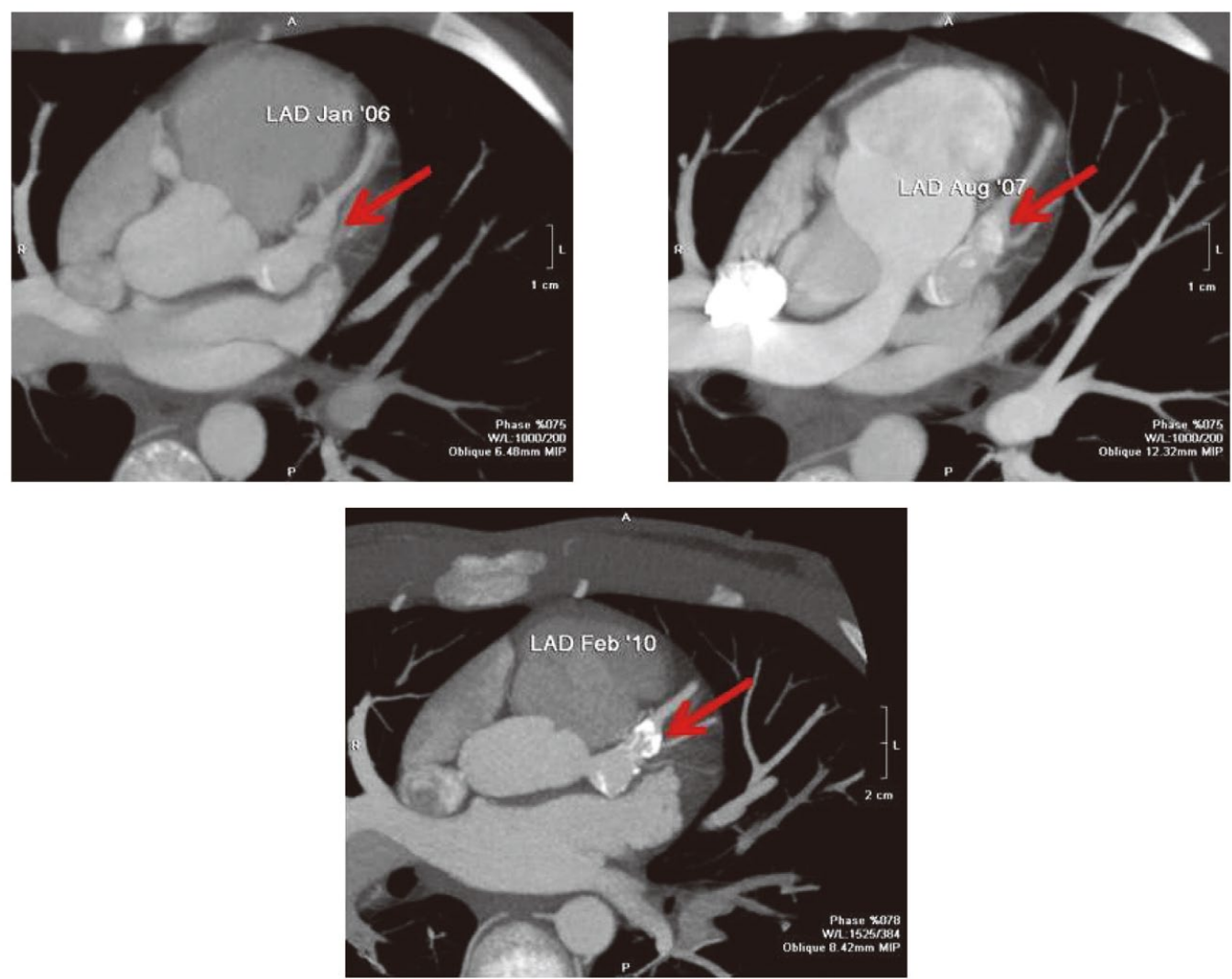

Figure 3. Serial CT angiograms showing progressive calcification in giant left and right coronary artery aneurysms at 7, 8, and 10 years after Kawasaki disease. Reproduced with permission from Kahn AM, et al. 62

luminal myofibroblastic proliferation, thrombosis, and calcification, (2) to assess the possibility of ongoing arterial wall inflammation, and (3) to assess ventricular function, wall motion abnormalities secondary to inducible ischemia, and myocardial fibrosis. Because these imaging procedures are being performed in young individuals who will require life-long monitoring, obtaining the best data with the least radiation exposure should be a guiding principle.

CTA has now virtually replaced diagnostic invasive angiography as the preferred modality for imaging the coronary arteries in adolescents and adults after KD. With advances in the technology and ECG-triggered prospective gating, image capture is of higher quality and with lower radiation doses $(<1 \mathrm{mSv})$ than in the past. ${ }^{63}$ Heart rate control continues to be important for optimal images during CTA and the use of $\beta$-blockade to both reduce and steady the heart rate yields the best quality scans. CTA is the preferred modality for assessment of morphologic changes in aneurysms and progressive calcification at most centers (Figure 3). CTA is also being investigated as a way to generate patient-specific computersimulated models of coronary artery aneurysms after KD, to assess the risk of thrombosis (Figure 4). ${ }^{64}$ However, invasive angiography is still the preferred modality for patients in whom an interventional procedure is contemplated or assessment of fractional flow reserve is needed to evaluate for possible surgical bypass grafting. If invasive angiography is performed, intravascular ultrasound or optical coherence tomography may aid in the assessment of thrombus burden and in determining the true diameter of the lumen for sizing of stents. ${ }^{65,66}$

Assessment of persistent arterial wall inflammation has become a topic of concern based on data from positron emission tomography (PET) with 18-fluorodeoxyglucose (FDG) combined with CT imaging, suggesting that in some individuals vascular wall inflammation may persist despite resolution of systemic signs of inflammation. ${ }^{67,68}$ Although PET/CT remain a research tool, because of the high radiation exposure $(>10 \mathrm{mSv})$, newer techniques combining PET with FDG and MRI that reduce the radiation exposure by $50 \%$ are being reported. ${ }^{69}$ Delayed-enhancement with contrast-enhanced MRI has been used to detect vascular wall inflammation in giant cell arteritis and Takayasu's arteritis and these techniques may have application in KD. ${ }^{70,71}$ The search continues for better biomarkers or imaging procedures that can identify individuals with persistent inflammation who may benefit from adjunctive therapies.

\section{Cardiac Magnetic Resonance Angiography (CMRA)}

CMRA has the advantage of no radiation exposure and the ability to assess ventricular volumes and cardiac function in addition to imaging the coronary arteries. However, at this juncture in the development of CMRA, many centers prefer CTA because of the rapid acquisition of images and shorter time in the scanner. Expertise in imaging the coronary arteries 


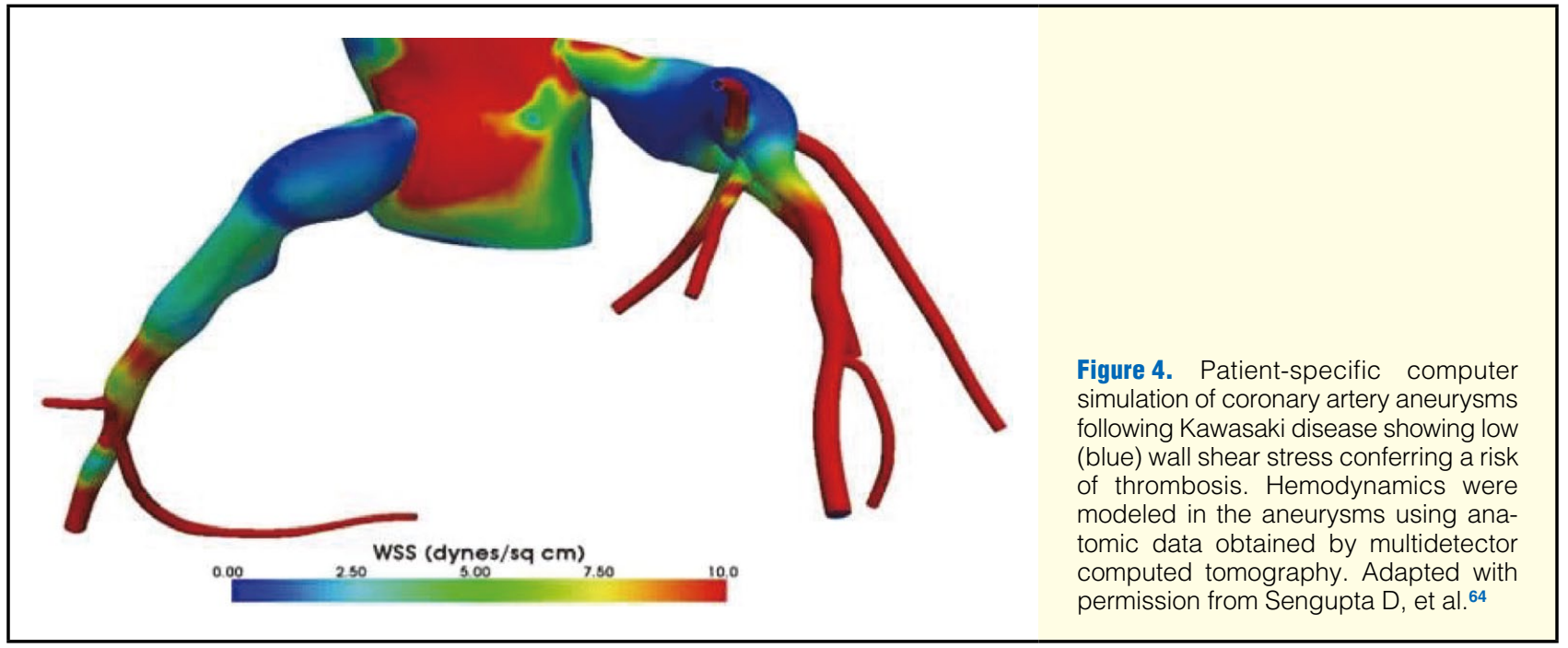

by CMRA remains highly variable among centers at this time. Noninvasive evaluation of diffuse myocardial fibrosis in adults late after KD in childhood remains a challenge. Autopsy data and examination of explanted hearts following cardiac transplantation in individuals with a history of KD demonstrate the development of extensive myocardial fibrosis secondary either to microvascular ischemia or diffuse post-inflammatory changes (Figure 5).,72 Although MRI with late gadolinium enhancement is effective in identifying regional wall abnormalities, detection of diffuse fibrosis has been more problematic, though recent studies offer promise. In studies of adults with either systemic sclerosis or rheumatoid arthritis, myocardial T1 mapping with extracellular volume quantification was effective in detecting persistent myocardial inflammation as well as diffuse fibrosis, and similar studies in KD are in progress. $^{73,74}$

\section{Biomarkers for Detection of Late CV Fibrosis}

Biomarkers for persistent vascular inflammation and myocardial fibrosis late after KD are actively being sought. One candidate is galectin-3 (Gal-3), a multifunctional protein in the extracellular matrix that has been associated with heart failure and myocardial fibrosis. In a study of 81 adult subjects with a history of KD, plasma levels of Gal-3 were elevated only in the 6 subjects with giant coronary artery aneurysms. ${ }^{75}$ Immunohistochemical staining of myocardium from autopsies and an explanted heart, decades after acute $\mathrm{KD}$, revealed diffuse myocardial fibrosis, as well as abundant staining of spindleshaped cells with a myofibroblast phenotype. The naturally occurring tetra-peptide, $\mathrm{N}$-acetyl-ser-asp-lys-pro (AcSDKP), has been shown in animal studies to reduce myocardial inflammation, prevent fibrosis mediated by Gal-3, ${ }^{76,77}$ and to inhibit epithelial-to-mesenchymal transition in cultured cells. ${ }^{78}$ Mineralocorticoid receptor antagonists have also been demonstrated to modulate Gal-3 expression after acute myocardial infarction and to reduce fibrosis mediated through the TGF $\beta$ SMAD3 signaling pathway. ${ }^{79}$ Genetic variation in this pathway influences both KD susceptibility and aneurysm formation. ${ }^{80}$ In the future, inhibition of Gal-3 with consequent reduction of TGF- $\beta$ signaling may be a strategy to reduce myocardial fibrosis in KD patients with severe coronary artery involvement and elevated serum levels of Gal-3.

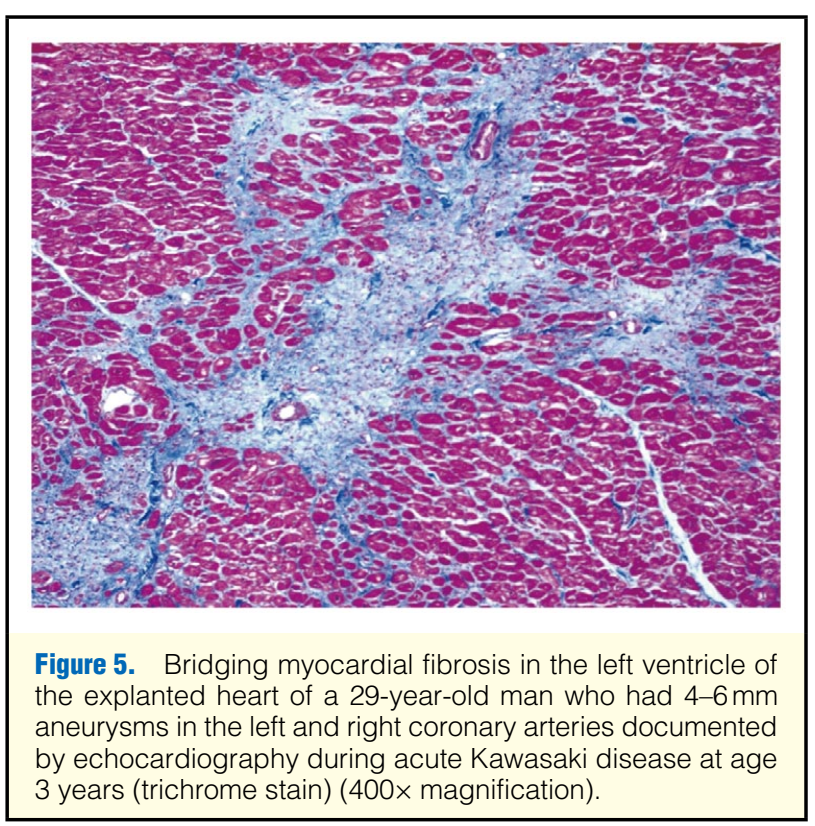

\section{Conclusions}

Adjunctive, noninvasive testing has the potential to improve our understanding of the vascular complications that may occur late after KD. Studies of noninvasive measures of vascular health have had mixed results to date, but a recurring theme is that persistence of coronary artery aneurysms is associated with abnormal results in other vascular beds, including peripheral endothelial cell function, vascular stiffness, and the carotid IMT. No studies have specifically addressed the question of whether the subset of patients with transiently dilated coronary arteries is also at increased risk. Measures of cardiac fibrosis, whether via MRI or biomarkers, is also promising for risk stratification but still in the early stages of development. In contrast to the unknown clinical role of measures of vascular function and fibrosis, advanced imaging techniques have the potential to immediately aid in risk stratification of individuals in whom the coronary artery history is unknown (CT coronary 
calcium scoring), or in whom there are known aneurysms that need more advanced assessment (CTA). Large, multicenter, long-term studies of patients after KD are needed to reach definitive conclusions regarding the optimal follow-up modalities, intensity, and duration for the majority of patients with KD.

\section{Disclosures}

None.

\section{Financial Support}

This work was supported, in part, by a grant from the Macklin Foundation (JCB and LBD), and from the American Heart Association, National Affiliate (LBD).

\section{References}

1. Suzuki A, Kamiya T, Kuwahara N, Ono Y, Kohata T, Takahashi O, et al. Coronary arterial lesions of Kawasaki disease: Cardiac catheterization findings of 1100 cases. Pediatr Cardiol 1986; 7: 3-9.

2. Kato H, Sugimura T, Akagi T, Sato N, Hashino K, Maeno Y, et al. Long-term consequences of Kawasaki disease: A 10- to 21-year follow-up study of 594 patients. Circulation 1996; 94: 1379-1385.

3. Burns JC, Daniels LB. Assessing vascular health after Kawasaki disease: A cautionary tale. J Am Coll Cardiol 2013; 62: 1122-1123.

4. Gordon JB, Kahn AM, Burns JC. When children with kawasaki disease grow up myocardial and vascular complications in adulthood. J Am Coll Cardiol 2009; 54: 1911-1920.

5. Gersony WM. The adult after kawasaki disease the risks for late coronary events. J Am Coll Cardiol 2009; 54: 1921-1923.

6. Hamburg NM, Keyes MJ, Larson MG, Vasan RS, Schnabel R, Pryde $\mathrm{MM}$, et al. Cross-sectional relations of digital vascular function to cardiovascular risk factors in the Framingham Heart Study. Circulation 2008; 117: 2467-2474.

7. Rubinshtein R, Kuvin JT, Soffler M, Lennon RJ, Lavi S, Nelson RE, et al. Assessment of endothelial function by non-invasive peripheral arterial tonometry predicts late cardiovascular adverse events. Eur Heart J 2010; 31: $1142-1148$.

8. Halcox JP, Schenke WH, Zalos G, Mincemoyer R, Prasad A, Waclawiw MA, et al. Prognostic value of coronary vascular endothelial dysfunction. Circulation 2002; 106: 653-658.

9. Shechter M, Issachar A, Marai I, Koren-Morag N, Freinark D, Shahar Y, et al. Long-term association of brachial artery flow-mediated vasodilation and cardiovascular events in middle-aged subjects with no apparent heart disease. Int J Cardiol 2009; 134: 52-58.

10. Haller MJ, Stein J, Shuster J, Theriaque D, Silverstein J, Schatz DA, et al. Peripheral artery tonometry demonstrates altered endothelial function in children with type 1 diabetes. Pediatr Diabetes 2007; 8: $193-198$

11. Matsuzawa Y, Sugiyama S, Sugamura K, Sumida H, Kurokawa H, Fujisue K, et al. Successful diet and exercise therapy as evaluated on self-assessment score significantly improves endothelial function in metabolic syndrome patients. Circ J 2013; 77: 2807-2815.

12. Keogh JB, Grieger JA, Noakes M, Clifton PM. Flow-mediated dilatation is impaired by a high-saturated fat diet but not by a high-carbohydrate diet. Arterioscler Thromb Vasc Biol 2005; 25: $1274-$ 1279.

13. George J, Carr E, Davies J, Belch JJ, Struthers A. High-dose allopurinol improves endothelial function by profoundly reducing vascular oxidative stress and not by lowering uric acid. Circulation 2006; 114: $2508-2516$

14. Widlansky ME, Gokce N, Keaney JF Jr, Vita JA. The clinical implications of endothelial dysfunction. J Am Coll Cardiol 2003; 42: $1149-1160$.

15. Huang AL, Silver AE, Shvenke E, Schopfer DW, Jahangir E, Titas MA, et al. Predictive value of reactive hyperemia for cardiovascular events in patients with peripheral arterial disease undergoing vascular surgery. Arterioscler Thromb Vasc Biol 2007; 27: 2113-2119.

16. Thijssen DH, Black MA, Pyke KE, Padilla J, Atkinson G, Harris RA, et al. Assessment of flow-mediated dilation in humans: A methodological and physiological guideline. Am J Physiol Heart Circ Physiol 2011; 300: H2-H12.

17. Celermajer DS. Reliable endothelial function testing: At our fingertips? Circulation 2008; 117: 2428-2430.

18. Anderson TJ. Prognostic significance of brachial flow-mediated vasodilation. Circulation 2007; 115: 2373-2375.

19. Hedetoft M, Olsen NV. Evaluation of endothelial function by peripheral arterial tonometry and relation with the nitric oxide pathway. Nitric Oxide 2014; 42: 1-8.
20. Hamburg NM, Palmisano J, Larson MG, Sullivan LM, Lehman BT, Vasan RS, et al. Relation of brachial and digital measures of vascular function in the community: The Framingham heart study. Hypertension 2011; 57: 390-396.

21. Yamakawa R, Ishii M, Sugimura T, Akagi T, Eto G, Iemura M, et al. Coronary endothelial dysfunction after Kawasaki disease: Evaluation by intracoronary injection of acetylcholine. J Am Coll Cardiol 1998; 31: 1074-1080.

22. Mitani Y, Okuda Y, Shimpo H, Uchida F, Hamanaka K, Aoki K, et al. Impaired endothelial function in epicardial coronary arteries after Kawasaki disease. Circulation 1997; 96: 454-461.

23. Dietz SM, Tacke CE, Hutten BA, Kuijpers TW. Peripheral endothelial (dys)function, arterial stiffness and carotid intima-media thickness in patients after Kawasaki disease: A systematic review and meta-analyses. PLoS One 2015; 10: e0130913, doi:10.1371/journal. pone.0130913.

24. Benetos A, Waeber B, Izzo J, Mitchell G, Resnick L, Asmar R, et al. Influence of age, risk factors, and cardiovascular and renal disease on arterial stiffness: Clinical applications. Am J Hypertens 2002; 15: $1101-1108$.

25. Laurent S, Boutouyrie P, Asmar R, Gautier I, Laloux B, Guize L, et al. Aortic stiffness is an independent predictor of all-cause and cardiovascular mortality in hypertensive patients. Hypertension 2001 ; 37: $1236-1241$.

26. Boutouyrie P, Tropeano AI, Asmar R, Gautier I, Benetos A, Lacolley $\mathrm{P}$, et al. Aortic stiffness is an independent predictor of primary coronary events in hypertensive patients: A longitudinal study. Hypertension 2002; 39: 10-15.

27. Mitchell GF, Hwang SJ, Vasan RS, Larson MG, Pencina MJ, Hamburg NM, et al. Arterial stiffness and cardiovascular events: The Framingham Heart Study. Circulation 2010; 121: 505-511.

28. Sutton-Tyrrell K, Najjar SS, Boudreau RM, Venkitachalam L, Kupelian V, Simonsick EM, et al. Elevated aortic pulse wave velocity, a marker of arterial stiffness, predicts cardiovascular events in well-functioning older adults. Circulation 2005; 111: 3384-3390.

29. Mattace-Raso FU, van der Cammen TJ, Hofman A, van Popele NM, Bos ML, Schalekamp MA, et al. Arterial stiffness and risk of coronary heart disease and stroke: The Rotterdam Study. Circulation 2006; 113: 657-663.

30. Kallio K, Jokinen E, Hamalainen M, Saarinen M, Volanen I, Kaitosaari T, et al. Decreased aortic elasticity in healthy 11-year-old children exposed to tobacco smoke. Pediatrics 2009; 123: e267e273, doi:10.1542/peds.2008-2659.

31. Iannuzzi A, Rubba P, Pauciullo P, Celentano E, Capano G, Sartorio $\mathrm{R}$, et al. Stiffness of the aortic wall in hypercholesterolemic children. Metabolism 1999; 48: 55-59.

32. O'Rourke MF, Staessen JA, Vlachopoulos C, Duprez D, Plante GE. Clinical applications of arterial stiffness; definitions and reference values. Am J Hypertens 2002; 15: 426-444.

33. Laurent S, Cockcroft J, Van Bortel L, Boutouyrie P, Giannattasio C, Hayoz D, et al. Expert consensus document on arterial stiffness: Methodological issues and clinical applications. Eur Heart J 2006; 27: $2588-2605$.

34. Vlachopoulos C, Aznaouridis K, Stefanadis C. Prediction of cardiovascular events and all-cause mortality with arterial stiffness: A systematic review and meta-analysis. J Am Coll Cardiol 2010; 55: $1318-1327$.

35. Willum-Hansen T, Staessen JA, Torp-Pedersen C, Rasmussen S, Thijs L, Ibsen H, et al. Prognostic value of aortic pulse wave velocity as index of arterial stiffness in the general population. Circulation 2006; 113: 664-670.

36. Hirai T, Sasayama S, Kawasaki T, Yagi S. Stiffness of systemic arteries in patients with myocardial infarction: A noninvasive method to predict severity of coronary atherosclerosis. Circulation 1989; 80: $78-86$.

37. Nunez F, Martinez-Costa C, Sanchez-Zahonero J, Morata J, Chorro FJ, Brines J. Carotid artery stiffness as an early marker of vascular lesions in children and adolescents with cardiovascular risk factors. Rev Esp Cardiol 2010; 63: 1253-1260.

38. Oguri M, Nakamura T, Tamanuki K, Akita C, Kitaoka C, Saikawa $\mathrm{Y}$, et al. Subclinical arterial stiffness in young children after Kawasaki disease. Cardiol Young 2014; 24: 87-94.

39. Cheung YF, Yung TC, Tam SC, Ho MH, Chau AK. Novel and traditional cardiovascular risk factors in children after Kawasaki disease: Implications for premature atherosclerosis. $\mathrm{J} \mathrm{Am} \mathrm{Coll} \mathrm{Cardiol}$ 2004; 43: 120-124.

40. Cheung YF, O K, Woo CW, Armstrong S, Siow YL, Chow PC, et al. Oxidative stress in children late after Kawasaki disease: Relationship with carotid atherosclerosis and stiffness. BMC Pediatr 2008; 8: 20 . 
41. Ooyanagi R, Fuse S, Tomita H, Takamuro M, Horita N, Mori M, et al. Pulse wave velocity and ankle brachial index in patients with Kawasaki disease. Pediatr Int 2004; 46: 398-402.

42. Cheung YF, Ho MH, Ip WK, Fok SF, Yung TC, Lau YL. Modulating effects of mannose binding lectin genotype on arterial stiffness in children after Kawasaki disease. Pediatr Res 2004; 56: 591-596.

43. Cheung YF, Wong SJ, Ho MH. Relationship between carotid intimamedia thickness and arterial stiffness in children after Kawasaki disease. Arch Dis Child 2007; 92: 43-47.

44. Cho HJ, Yang SI, Kim KH, Kim JN, Kil HR. Cardiovascular risk factors of early atherosclerosis in school-aged children after Kawasaki disease. Korean J Pediatr 2014; 57: 217-221.

45. Niboshi A, Hamaoka K, Sakata K, Yamaguchi N. Endothelial dysfunction in adult patients with a history of Kawasaki disease. Eur J Pediatr 2008; 167: 189-196.

46. O'Leary DH, Polak JF, Kronmal RA, Manolio TA, Burke GL, Wolfson SK Jr. Carotid-artery intima and media thickness as a risk factor for myocardial infarction and stroke in older adults: Cardiovascular Health Study Collaborative Research Group. N Engl J Med 1999; 340: 14-22.

47. Chambless LE, Heiss G, Shahar E, Earp MJ, Toole J. Prediction of ischemic stroke risk in the Atherosclerosis Risk in Communities Study. Am J Epidemiol 2004; 160: 259-269.

48. Chambless LE, Folsom AR, Sharrett AR, Sorlie P, Couper D, Szklo $\mathrm{M}$, et al. Coronary heart disease risk prediction in the Atherosclerosis Risk in Communities (ARIC) study. J Clin Epidemiol 2003; 56: $880-890$.

49. Bots ML, Hoes AW, Koudstaal PJ, Hofman A, Grobbee DE. Common carotid intima-media thickness and risk of stroke and myocardial infarction: The Rotterdam Study. Circulation 1997; 96: 1432 1437.

50. Peters SA, Grobbee DE, Bots ML. Carotid intima-media thickness: A suitable alternative for cardiovascular risk as outcome? Eur $J$ Cardiovasc Prev Rehabil 2011; 18: 167-174.

51. Lorenz MW, Markus HS, Bots ML, Rosvall M, Sitzer M. Prediction of clinical cardiovascular events with carotid intima-media thickness: A systematic review and meta-analysis. Circulation 2007; 115: 459-467.

52. Bots ML, Sutton-Tyrrell K. Lessons from the past and promises for the future for carotid intima-media thickness. $J$ Am Coll Cardiol 2012; 60: $1599-1604$

53. Tzou WS, Douglas PS, Srinivasan SR, Bond MG, Tang R, Li S, et al. Distribution and predictors of carotid intima-media thickness in young adults. Prev Cardiol 2007; 10: 181-189.

54. Urbina EM, Williams RV, Alpert BS, Collins RT, Daniels SR, Hayman L, et al. Noninvasive assessment of subclinical atherosclerosis in children and adolescents: Recommendations for standard assessment for clinical research: A scientific statement from the American Heart Association. Hypertension 2009; 54: 919-950.

55. Jourdan C, Wuhl E, Litwin M, Fahr K, Trelewicz J, Jobs K, et al. Normative values for intima-media thickness and distensibility of large arteries in healthy adolescents. J Hypertens 2005; 23: 1707 1715.

56. Noto N, Okada T, Yamasuge M, Taniguchi $\mathrm{K}$, Karasawa $\mathrm{K}$, Ayusawa M, et al. Noninvasive assessment of the early progression of atherosclerosis in adolescents with Kawasaki disease and coronary artery lesions. Pediatrics 2001; 107: 1095-1099.

57. Noto N, Okada T, Karasawa K, Ayusawa M, Sumitomo N, Harada $\mathrm{K}$, et al. Age-related acceleration of endothelial dysfunction and subclinical atherosclerosis in subjects with coronary artery lesions after Kawasaki disease. Pediatr Cardiol 2009; 30: 262-268.

58. Noto N, Okada T, Abe Y, Miyashita M, Kanamaru H, Karasawa K, et al. Characteristics of earlier atherosclerotic involvement in adolescent patients with Kawasaki disease and coronary artery lesions: Significance of gray scale median on B-mode ultrasound. Atherosclerosis 2012; 222: 106-109.

59. Selamet Tierney ES, Gal D, Gauvreau K, Baker AL, Trevey S, O'Neill SR, et al. Vascular health in Kawasaki disease. J Am Coll Cardiol 2013; 62: 1114-1121.

60. Valenti V, B OH, Heo R, Cho I, Schulman-Marcus J, Gransar H, et al. A 15-year warranty period for asymptomatic individuals without coronary artery calcium: A prospective follow-up of 9,715 individuals. JACC Cardiovasc Imaging 2015; 8: 900-909.

61. Kaichi S, Tsuda E, Fujita H, Kurosaki K, Tanaka R, Naito H, et al. Acute coronary artery dilation due to Kawasaki disease and subsequent late calcification as detected by electron beam computed tomography. Pediatr Cardiol 2008; 29: 568-573.

62. Kahn AM, Budoff MJ, Daniels LB, Jimenez-Fernandez S, Cox AS, Gordon JB, et al. Calcium scoring in patients with a history of
Kawasaki disease. JACC Cardiovasc Imaging 2012; 5: 264-272.

63. Ghoshhajra BB, Lee AM, Engel LC, Celeng C, Kalra MK, Brady TJ, et al. Radiation dose reduction in pediatric cardiac computed tomography: Experience from a tertiary medical center. Pediatr Cardiol 2014; 35: $171-179$

64. Sengupta D, Kahn AM, Burns JC, Sankaran S, Shadden SC, Marsden AL. Image-based modeling of hemodynamics in coronary artery aneurysms caused by Kawasaki disease. Biomech Model Mechanobiol 2012; 11: 915-932.

65. Dionne A, Ibrahim R, Gebhard C, Bakloul M, Selly JB, Leye M, et al. Coronary wall structural changes in patients with kawasaki disease: New insights from optical coherence tomography (OCT). J Am Heart Assoc 2015; 4: e001939, doi:10.1161/JAHA.115.001939.

66. Mitani Y, Ohashi H, Sawada H, Ikeyama Y, Hayakawa H, Takabayashi S, et al. In vivo plaque composition and morphology in coronary artery lesions in adolescents and young adults long after Kawasaki disease: A virtual histology-intravascular ultrasound study. Circulation 2009; 119: 2829-2836.

67. Suda K, Tahara N, Honda A, Iemura M, Yoshimoto H, Kudo Y, et al. Persistent peripheral arteritis long after Kawasaki disease: Another documentation of ongoing vascular inflammation. Int J Cardiol 2015; 180: $88-90$.

68. Suda K, Tahara N, Kudo Y, Yoshimoto H, Iemura M, Ueno T, et al. Persistent coronary arterial inflammation in a patient long after the onset of Kawasaki disease. Int J Cardiol 2012; 154: 193-194.

69. Gatidis S, Schmidt H, Gucke B, Bezrukov I, Seitz G, Ebinger M, et al. Comprehensive oncologic imaging in infants and preschool children with substantially reduced radiation exposure using combined simultaneous $18 \mathrm{~F}$-fluorodeoxyglucose positron emission tomography/magnetic resonance imaging: A direct comparison to $18 \mathrm{~F}$-fluorodeoxyglucose positron emission tomography/computed tomography. Invest Radiol 2015 August 24, doi:10.1097/RLI.0000000000000200.

70. Bley TA, Wieben O, Uhl M, Thiel J, Schmidt D, Langer M. Highresolution MRI in giant cell arteritis: Imaging of the wall of the superficial temporal artery. Am J Roentgenol 2005; 184: 283-287.

71. Desai MY, Stone JH, Foo TK, Hellmann DB, Lima JA, Bluemke DA. Delayed contrast-enhanced MRI of the aortic wall in Takayasu's arteritis: Initial experience. Am J Roentgenol 2005; 184: 1427-1431.

72. Shimizu C, Sood A, Lau HD, Oharaseki T, Takahashi K, Krous HF, et al. Cardiovascular pathology in 2 young adults with sudden, unexpected death due to coronary aneurysms from Kawasaki disease in childhood. Cardiovasc Pathol 2015; 24: 310-316.

73. Ntusi NA, Piechnik SK, Francis JM, Ferreira VM, Rai AB, Matthews $\mathrm{PM}$, et al. Subclinical myocardial inflammation and diffuse fibrosis are common in systemic sclerosis: A clinical study using myocardial T1-mapping and extracellular volume quantification. $J$ Cardiovasc Magn Reson 2014; 16: 21.

74. Ntusi NA, Piechnik SK, Francis JM, Ferreira VM, Matthews PM, Robson MD, et al. Diffuse myocardial fibrosis and inflammation in rheumatoid arthritis: Insights from CMR T1 mapping. JACC Cardiovasc Imaging 2015; 8: 526-536.

75. Numano F, Shimizu C, Jimenez-Fernandez S, Vejar M, Oharaseki T, Takahashi K, et al. Galectin-3 is a marker of myocardial and vascular fibrosis in Kawasaki disease patients with giant aneurysms. Int $J$ Cardiol 2015; 201: 429-437.

76. Sharma U, Rhaleb NE, Pokharel S, Harding P, Rasoul S, Peng H, et al. Novel anti-inflammatory mechanisms of N-Acetyl-Ser-Asp-LysPro in hypertension-induced target organ damage. Am J Physiol Heart Circ Physiol 2008; 294: H1226-H1232.

77. Liu YH, D'Ambrosio M, Liao TD, Peng H, Rhaleb NE, Sharma U, et al. N-acetyl-seryl-aspartyl-lysyl-proline prevents cardiac remodeling and dysfunction induced by galectin-3, a mammalian adhesion/ growth-regulatory lectin. Am J Physiol Heart Circ Physiol 2009; 296: $\mathrm{H} 404-\mathrm{H} 412$

78. Deng H, Yang F, Xu H, Sun Y, Xue X, Du S, et al. Ac-SDKP suppresses epithelial-mesenchymal transition in A549 cells via HSP27 signaling. Exp Mol Pathol 2014; 97: 176-183.

79. Lax A, Sanchez-Mas J, Asensio-Lopez MC, Fernandez-Del Palacio MJ, Caballero L, Garrido IP, et al. Mineralocorticoid receptor antagonists modulate galectin-3 and interleukin-33/ST2 signaling in left ventricular systolic dysfunction after acute myocardial infarction. JACC Heart Fail 2015; 3: 50-58.

80. Shimizu C, Jain S, Davila S, Hibberd ML, Lin KO, Molkara D, et al. Transforming growth factor-beta signaling pathway in patients with Kawasaki disease. Circ Cardiovasc Genet 2011; 4: 16-25.

81. Schillaci G, Sarchielli P, Corbelli I, Pucci G, Settimi L, Mannarino MR, et al. Aortic stiffness and pulse wave reflection in young subjects with migraine: A case-control study. Neurology 2015; 75: 960-966. 